\title{
Green synthesis of silver nanoparticles and its antibacterial activity using fungus Talaromyces purpureogenus isolated from Taxus baccata Linn.
}

\author{
Ankush Sharma ${ }^{{ }^{*}} \mathbb{D}$, Anand Sagar ${ }^{1}$, Jagriti Rana ${ }^{1}$ and Reena Rani ${ }^{2}$
}

\begin{abstract}
The present study is focused on the synthesis of silver nanoparticles (AgNPs) utilizing endophytic fungus Talaromyces purpureogenus, isolated from Taxus baccata Linn. Extracellular extract of Talaromyces purpureogenus has shown occurrence of secondary metabolites viz. terpenoids and phenols. Gas chromatography-mass spectroscopy analysis showed the presence of 16 compounds. Techniques like Ultraviolet-visible spectroscopy, Fourier transform infrared spectroscopy, dynamic light scattering, field emission gun scanning electron microscopy, high-resolution transmission electron microscopy, energy-dispersive $X$-ray spectroscopy and $X$-ray diffraction were employed to characterize the synthesized AgNPs. UV-Vis spectroscopy showed sharp peaks at 380-470 nm which indicates the presence of metallic silver. FTIR analysis showed the presence of various functional groups like phenols, hydroxyl groups, and primary amines. In DLS, Z-average size and Pdl of synthesized AgNPs were $240.2 \mathrm{r.nm}$ and 0.720 respectively, with zeta potential - $19.6 \mathrm{mV}$. In FEG-SEM and HRTEM the spherical AgNPs showed diameter in the range of 30-60 nm. In EDS analysis the weight percent of $\mathrm{Ag}$ is $67.26 \%$ and atomic percent is $43.13 \%$. From XRD analysis the size of AgNPs was found to be $49.3 \mathrm{~nm}$ with face-centered cubic crystalline nature of fungal synthesized AgNPs. These nanoparticles have shown significant antibacterial activity against tested strains viz. Listeria monocytogenes (13 $\pm 0.29 \mathrm{~mm})$, Escherichia coli $(17 \pm 0.14 \mathrm{~mm})$, Shigella dysenteriae $(18 \pm 0.21 \mathrm{~mm})$ and Salmonella typhi $(14 \pm 0.13 \mathrm{~mm})$. These synthesized AgNPs have shown effective free radical scavenging activity against 2,2'-diphenyl-1-picrylhydrazyl. The present study showed that the endophytic fungus Talaromyces purpureogenus can be used as a prominent source to synthesize AgNPs by using biological, ecofriendly, and in a non-toxic way accompanied by antibacterial and antioxidant properties which further can reduce the harvesting pressure faced by Taxus baccata.
\end{abstract}

Keywords: Talaromyces purpureogenus, Taxus baccata Linn., AgNPs, DLS, XRD, HRTEM-EDS, Antibacterial and antioxidant activity

\footnotetext{
*Correspondence: theankushsharma@gmail.com

1 Department of Biosciences, Himachal Pradesh University, Summerhill,

Shimla 171005, Himachal Pradesh, India

Full list of author information is available at the end of the article
} original author(s) and the source, provide a link to the Creative Commons licence, and indicate if changes were made. The images or other third party material in this article are included in the article's Creative Commons licence, unless indicated otherwise in a credit line to the material. If material is not included in the article's Creative Commons licence and your intended use is not permitted by statutory regulation or exceeds the permitted use, you will need to obtain permission directly from the copyright holder. To view a copy of this licence, visit http://creativecommons.org/licenses/by/4.0/. 


\section{Graphical Abstract}

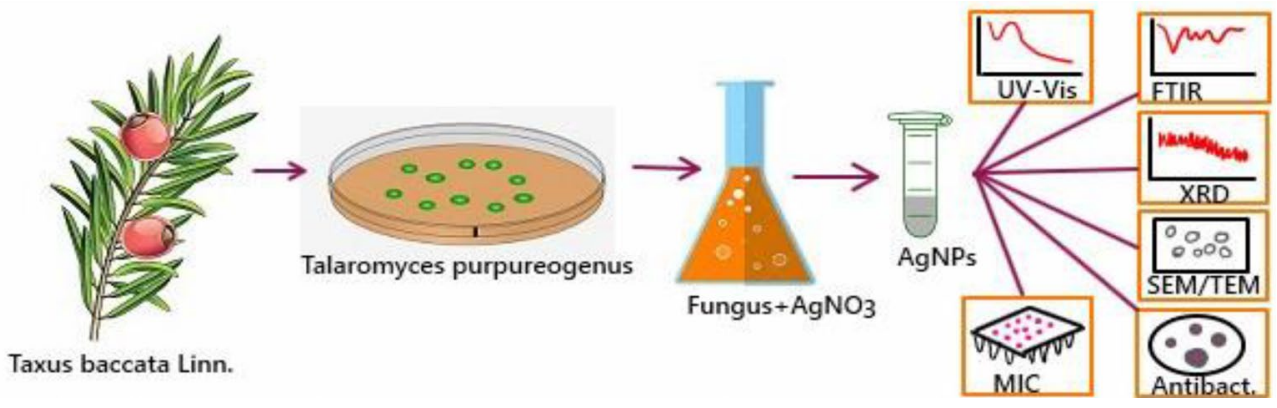

\section{Introduction}

Gymnosperms are majorly exploited for their wood quality, resins, gums, and medicinal values [1]. Taxus baccata Linn. a gymnosperm found at a height of 2300-2800 m in the western and eastern Himalayas, has innumerable medicinal utilities such as those used in kidney disease, Alzheimer [2], bronchitis, asthma, and as an aphrodisiac [3]. Apart from these uses bark is used as salted tea by the local community [4] paste of the bark is used to cure headaches and as a plaster to repair the fractured bones [5]. The plant is supposed to be a good source of anticancerous drugs Taxol or Paclitaxel [6, 7]. However, the utilitarian values of this plant are causing its degradation in several ways. Lack of good harvesting techniques and statutory procedures, the leaves and bark are harvested callously leading to the injudicious exploitation of the plants. Also, the excessive stress on this plant for its resources for commercial uses and habitat disturbances are resulting in its disappearance at a rapid rate [8-10]. Taxus baccata is a splendid host of many types of microorganisms such as endophytic bacteria (Burkholderia and Enterobacter) [11], endophytic fungi (Aspergillus, Fusarium, Penicillium, Trichoderma, etc. $[12,13]$ and mycorrhizae [12, 14]. Endophytic fungi reside in the plant's internal tissues without causing any visible harm to them. These fungi have been reported to synthesize a variety of chemical compounds called secondary metabolites, reported to possess antibacterial, antifungal, anti-cancerous, antioxidant, and various other important activities [15-17].

The tissue extracts of Taxus baccata are the source of many medicines. A further advanced step has been employed where nano-sized particles coated with tissue extracts of Taxus baccata work more precisely than the ordinary processes $[18,19]$. However, this dependency on the plant can be minimized by the use of fungi for the production of anti-cancerous materials encapsulated on nanoparticles [20-22]. Nanobiotechnology has emerged as a promising technology to develop new therapeutically active nanomaterials; nanoparticles are one of them [23]. Nanoparticles exhibit special optical, electronic, and magnetic properties [24]. Nanoparticles having exceptionally tiny size result in strong adherence to the target sites and are not easily washed away in the system, thus increasing their residence time on the targets such as cancer cells. This increase in retention time results in better drug delivery and cure to the problem [25].

Exposure of secondary metabolites reduces the metallic ions into nanosized metallic particles [26]. Among other metallic nanoparticles silver nanoparticles has been immensely worked upon due to their biocompatibility [27]. Silver nanoparticles possess variety of beneficial properties including optical, good electrical conductivity and biological properties. Applications of silver nanoparticles is increasing as antibacterial agents, sensors, food industry and as anticancerous agents. Biologically synthesized silver nanoparticles possess high solubility, stability, high yield and antimicrobial properties. The process of AgNPs synthesis is also non-toxic and cost effective [28-31]. Synthesis of many fungus-coated metallic nanoparticles has been reported [32-36]. A very important fungus Penicillium sp. isolated from a useful plant named Glycosmis mauritiana, has been reported to effectively produce AgNPs which are showing good quality antioxidant, antimicrobial, anti-inflammatory, and tyrosinase inhibitory activity [37]. Fungus Talaromyces pupureogenus isolated from Pinus sp. resulted in the formation of AgNPs with an average size of $25 \mathrm{~nm}$ and has shown strong antibacterial and antioxidant properties [22]. Taxus baccata is also considered to be a host of many fungal species [12, 38]. AgNPs of size 5-70 nm with spherical shape were obtained from fungus Nemania sp. isolated from Taxus baccata. These AgNPs have shown prominent antibacterial activity against certain harmful bacteria [38]. So, in the present study fungus, Talaromyces purpureogenus isolated from a gymnosperm Taxus baccata has been utilized for the synthesis of AgNPs and the characterization of these nanoparticles has been done 
using various spectrophotometric techniques. Further, the activity of these AgNPs has been tested as antibacterial and antioxidant agents.

\section{Experimental}

Isolation and identification of endophytic fungi

Healthy tissues (leaf, stem, and roots) of Taxus baccata were collected from the Choordhar region of Shimla District of Himachal Pradesh, India. The tissues were sterilized in the lab by using the method of Schulz et al. [39]. The plant tissues were properly washed under running tap water. The surface sterilization was done by first immersing in $70 \%$ ethanol for $60 \mathrm{~s}$, followed by sodium hypochlorite (4\% of available chlorine) for $3 \mathrm{~min}$ and then dipped in $75 \%$ of ethanol for $30 \mathrm{~s}$. For the sterilization of leaves, the method of Suryanarayan and Thennarasan [40] was followed. The leaf samples were cut into pieces of different sizes. Finally, sterilized samples were rinsed with autoclaved distilled water three times and were allowed to dry in laminar airflow. The plant samples such as root, bark, stem, and leaves were cut into small pieces and placed on the Petri plates containing potato dextrose agar (PDA, Himedia Pvt. Ltd. India). The PDA was also supplied with streptomycin $(100 \mathrm{mg} / \mathrm{L}$, Himedia Pvt. Ltd. India) to prevent endophytic bacterial growth. Petri plates were incubated at $28 \pm 2{ }^{\circ} \mathrm{C}$. These Petri plates were observed on regular basis for endophytic fungal growth. A pure culture of the endophytic fungi was obtained after continuous transfer of hyphal tips on fresh PDA plates. Morphological identification of the isolated endophytic fungi was performed at ARI Pune, India (Agharkar Research Institute). Out of 08 endophytic fungi 07 (Aspergillus flavus, A. nidulans, A. niger, Penicillium viridicatum etc.) belonged to family Aspergillaceae and one (Talaromyces purpureogenus) to Trichomaceae. Molecular-level identification of isolated fungi was carried by PCR using ITS4 and ITS5 primer pair. The identification was being carried out at ARI Pune, India (Agharkar Research Institute). T. purpureogenus formed soft and cottony ascocarps with interwoven hyphae. The fruiting body of this particular fungus were yellowish in colour. Structures like conidia, metulae and phialides were observed carefully. The phialides were supported by the metulae. Further, identification of the fungus was done when the genomic DNA was isolated in pure form from the culture. The ITS-rDNA partial gene was successfully amplified using ITS4 and ITS5. The sequencing PCR was set up with ABI-BigDye ${ }^{\circledR}$ Terminatorv 3.1 Cycle Sequencing Kit. The raw sequence obtained from ABI 3100 automated DNA sequencer was manually edited for inconsistency. The sequence data was aligned with publicly available sequences and analyzed to reach identity. All isolated endophytic fungi were screened for antibacterial activity and T. purpureogenus showed significant activity against tested bacterial strains. Therefore, it was further selected for the synthesis of AgNPs.

\section{Preparation of endophytic fungal extracts}

T. purpureogenus was inoculated in potato dextrose broth (PDB) and was incubated at $28 \pm 2{ }^{\circ} \mathrm{C}$ on an incubator shaker with $150 \mathrm{rpm}$ for 6 days. The growth of the fungus was observed regularly. This fungal biomass was filtered with the help of Whatman filter paper no. 1. This filtered mass was washed 3 times with distilled water to remove the media. For the preparation of endophytic fungal extracts, two standard procedures [41, 42] were used. The harvested fungal mass was weighed and $20 \mathrm{~g}$ of it was transferred to a $500 \mathrm{~mL}$ Erlenmeyer flask containing $100 \mathrm{~mL}$ of distilled water. These flasks were incubated at $28 \pm 2{ }^{\circ} \mathrm{C}$ for $24 \mathrm{~h}$ with the $180 \mathrm{rpm}$ shaking for the extraction. At the end of this period, the cell-free filtrate was filtered using Whatman No. 1 filter paper and used in further experimental processes.

\section{Screening for secondary metabolites}

For the screening of secondary metabolites, the method of Radji et al. [43] was followed with slight modifications. Small rectangular blocks from the agar plates containing fungal mycelium were cut and inoculated into a $250 \mathrm{~mL}$ Erlenmeyer flask containing $100 \mathrm{~mL}$ of (PDB). After pouring the flasks were incubated at $25-27{ }^{\circ} \mathrm{C}$ for 21 days with occasional shaking. After the defined period, the broth culture was filtered to separate mycelium and filtrate. The extraction was performed with majorly 05 organic solvents and after standardization ethyl acetate was preferred as extraction solvent because of better results as compared to other organic solvents. Since, ethyl acetate is less polar than alcoholic extract, it dissolves the hydrocarbon rich secondary metabolites much better than alcohols. Insights into previous works also substantiated the selection of the solvent $[44,45]$. An equal volume of ethyl acetate was added to the filtrate. The solution was mixed well for 10-15 $\mathrm{min}$ and then kept for 5-10 min. The formation of two clear immiscible layers was observed. The upper layer of ethyl acetate was separated using a separating funnel as it contains the extracted compounds. Rotary evaporation supplemented with reduced pressure at $35-40{ }^{\circ} \mathrm{C}$ was done to remove the solvents and resulting in a concentrated extract. Further, the extract was dissolved in DMSO and stored in the refrigerator. The qualitative screening of phytochemicals present in the fungal extract was done by following the standard procedure of Devi et al. [46]. 


\section{GCMS analysis of fungal extract}

Mass spectrum of compounds was done by gas chromatography-mass spectroscopy (GCMS analyser-Thermo Scientific TSQ 8000 Gas Chromatograph-Mass Spectrometer). It was paired with GC TRACE-1300 GC. The ion source was EI source programmable to $350{ }^{\circ} \mathrm{C}$ with mass range 2.1100 a.m.u and column temperature $400{ }^{\circ} \mathrm{C}$. The column used was Rtx -5 of $30 \mathrm{~m}$ in length, $0.25 \mathrm{~mm}$ column inside diameter with $0.25 \mu \mathrm{m}$ film coating. The sample was filtered through Whatman Filter Device $(0.2 \mu \mathrm{m})$. Helium $(99.99 \%)$ gas was used as the carrier with a flow rate of $1 \mathrm{~mL} / \mathrm{min}$ in split mode. A volume of $1 \mu \mathrm{L}$ of the fungal extract was injected into the column with $280{ }^{\circ} \mathrm{C}$ inlet temperature. The temperature of the oven was initially set at $70{ }^{\circ} \mathrm{C}$ for 2 min and then it was elevated at a rate of $7{ }^{\circ} \mathrm{C} / \mathrm{min}$ up to $320^{\circ} \mathrm{C}$. The temperature of ion sources was maintained at $250{ }^{\circ} \mathrm{C}$. The mass spectrum of compounds present in the fungal extract was obtained by electron ionization at $70 \mathrm{eV}$ and the detector operates in scan mode $30-500 \mathrm{Da}$ atomic units. The total running time was 22.77 min with 6694 scans. The obtained spectrum of the extract was compared with the database of the National Institute of Science and Technology (NIST) library [47].

\section{Biosynthesis and characterization of AgNPs}

For the synthesis of AgNPs from Talaromyces purpureogenus, method of Sandhu et al. [48] was opted with little modifications. An aqueous solution of silver nitrate ( $80 \mathrm{~mL} ; 2 \mathrm{mM}$ ) was mixed with $20 \mathrm{~mL}$ of fungal extract and incubated at room temperature. Flasks were kept covered with aluminium foil to reduce the chances of photo-oxidation. Prior standardization of reaction mixture was done before proceeding towards the final process of nanoparticle synthesis. According to the standardization the time limits were finalized which were corresponding to the color change and AgNPs synthesis. The aliquots of samples were withdrawn subsequently after $12 \mathrm{~h}, 24 \mathrm{~h}, 36 \mathrm{~h}, 48 \mathrm{~h}, 72 \mathrm{~h}$, and $96 \mathrm{~h}$ for observing the color change from transparent to dark brown.

For the determination of successful synthesis of AgNPs UV-Vis spectrophotometry (Shimadzu UV-Vis Spectrophotometer) was done by measuring the absorbance of the solution at different time intervals $(1,12,24,48,72$, and $96 \mathrm{~h}$ ) at $300-700 \mathrm{~nm}$. After $48-72 \mathrm{~h}$ of reaction, the mixture was centrifuged at $12,000 \mathrm{rpm}$ for $15 \mathrm{~min}$. The unbounded capping material was removed by repeated washing (4 times) with double distilled water. Thereafter, the pellet was lyophilized to get dry powder of the material. There are different types of functional groups involved in the stabilization and capping of synthesized nanoparticles which were detected by using FTIR. Characteristic peaks were recorded in $400-4000 \mathrm{~cm}^{-1}$ at resolution $4 \mathrm{~cm}^{-1}$. The sample was analyzed twice. The size was analyzed with the help of Dynamic Light Scattering analysis (DLS-Malvern).Surface morphological studies were done using FEGSEM technique. However, for the elemental analysis, FEGSEM-EDS was used. For the analysis of the shape and size of synthesized nanoparticles the AgNPs powder was suspended in ethanol for High-Resolution Transmission Electron Microscopy (HRTEM) and the presence of specific metallic groups was found with the help of HRTEM-EDX (energy-dispersive X-ray spectroscopy. Finally, XRD was used for the analysis of morphology and crystalline nature of AgNPs in a wide range of Bragg angles $2 \theta$ at scanning rate $30-80$ at $0.041 / \mathrm{min}$ with a time constant of $2 \mathrm{~s}$.

\section{Antibacterial activity}

To determine the antibacterial activity of AgNPs disc diffusion method was used as described by Brumfitt et al. [49]. This method was preferred over other methods based on literature, its promising and precise results [22]. All the bacterial strains (Listeria monocytogenes, Shigella dysenteriae, E. coli, and Salmonella typhi) were cultured in $10 \mathrm{~mL}$ of MHB in $50 \mathrm{~mL}$ Erlenmeyer flask for $24 \mathrm{~h}$ at $37^{\circ} \mathrm{C}$. Fifty $\mu \mathrm{L}$ of the bacterial cell suspension was spread over the MHA plates. Further, discs of $6 \mathrm{~mm}$ diameter were prepared from Whatman filter paper-3 which was further autoclaved and sterilized. These discs were dipped in different concentrations of solution of AgNPs. For positive control discs were supplied with antibiotics (Vanomycin and Ampicillin, $0.1 \mathrm{mg} / \mathrm{mL}$ ). The plates with antibiotics were used as positive control and those with DMSO were used as a negative control. These paper discs were placed on each plate which was further incubated at $37{ }^{\circ} \mathrm{C}$ for $24 \mathrm{~h}$. The antibacterial activity of AgNPs was measured as a clear zone of inhibition $(\mathrm{mm})$ using a vernier caliper.

The lowest concentration of an antibacterial agent to inhibit/prevent the growth of bacterial growth is called minimum inhibitory concentration (MIC). For the determination of MIC values of synthesized AgNPs microbroth dilution method of Sarkar et al. [50] was followed. Fifty $\mu \mathrm{L}$ of each sterile nutrient broth and normal saline was added to each well of the micro-titre plate. Now $50 \mu \mathrm{L}$ of nanoparticle solution was dissolved in DMSO $(25 \mathrm{mg} / \mathrm{mL})$. This $50 \mu \mathrm{L}$ was added to the first row of the micro-titre plate followed by serial dilution across the plate. Ten $\mu \mathrm{l}$ of each resazurin dye (indicator) and bacterial inoculums were added to each well. Plates were wrapped properly in a cling film to prevent the process of dehydration of bacteria and incubated at $37^{\circ} \mathrm{C}$ for $24 \mathrm{~h}$. These experiments were performed in duplicates to avoid any sort of error. A change in the color of the solution in 
the well was observed. If the color changes from purple to pink or colorless it indicated that bacteria have grown in it. The lowest concentration at which no color change was observed was considered as MIC value of AgNPs.

\section{Antioxidant assays}

For the determination of antioxidant potential of $T$. purpureogenus and synthesized AgNP's two assays viz. DPPH assay and reducing power assay were performed.

\section{DPPH (1, 1-diphenyl-2-picrylhydrazyl) free radical scavenging activity}

The antioxidant activity of the synthesized silver nanoparticles was determined by DPPH (1,1-diphenyl-2-picryl-hydrazyl) free radical scavenging assay as given by Blois [51]. One $\mathrm{mL}$ of extract prepared in $10 \%$ DMSO of different concentrations $(30 \mu \mathrm{g} / \mathrm{mL}, 60 \mu \mathrm{g} / \mathrm{mL}, 90 \mu \mathrm{g} / \mathrm{mL}$, $120 \mu \mathrm{g} / \mathrm{mL}$ and $150 \mu \mathrm{g} / \mathrm{mL}$ ) along with standard made up of DPPH + DMSO. One $\mathrm{mL}$ of $0.3 \mathrm{mM} \mathrm{DPPH}$ was added to it under dark conditions and was incubated for $30 \mathrm{~min}$ in dark. The absorbance was taken at $517 \mathrm{~nm}$ by UV-Vis spectrophotometer (UV-1800 Shimadzu). Ascorbic acid was used as reference or standard with same concentrations $(30 \mu \mathrm{g} / \mathrm{mL}, 60 \mu \mathrm{g} / \mathrm{mL}, 90 \mu \mathrm{g} / \mathrm{mL}, 120 \mu \mathrm{g} / \mathrm{mL}$ and $150 \mu \mathrm{g} / \mathrm{mL}$ ). The percent inhibition was calculated by the formula given below:

$$
\% \text { inhibition }=\frac{\mathrm{Abs}_{(\text {Control })}-\mathrm{Abs}_{(\text {sample })} \times 100}{\mathrm{Abs}_{(\mathrm{Control})}}
$$

The amount of extract that quenches $50 \%$ free radicals of DPPH is called its $\mathrm{IC}_{50}$ value. $\mathrm{IC}_{50}$ value $(\mu \mathrm{g} / \mathrm{mL})$ was determined by plotting a graph of $\%$ inhibition against different concentrations of extracts.

\section{Reducing power assay}

For the estimation of reductive potential of the fungal extract and AgNPs the method of Oyaizu [52] was followed. Ascorbic acid was taken as standard. One $\mathrm{mL}$ of distilled water was mixed with fungal extracts/AgNPs and standard $(1 \mathrm{mg} / \mathrm{mL})$. This solution was further mixed with phosphate buffer $(2.5 \mathrm{~mL}, 0.2 \mathrm{~mol} / \mathrm{L}, \mathrm{pH} 6.6)$ and potassium ferricyanide $(2.5 \mathrm{~mL}, 1 \% \mathrm{w} / \mathrm{v})$ was added to the mixture. The solution was mixed properly and centrifuged for $10 \mathrm{~min}$ at $3000 \mathrm{rpm}$. Then, $2.5 \mathrm{~mL}$ of supernatant was mixed with $2.5 \mathrm{~mL}$ of distilled water and $0.5 \mathrm{~mL}$ of $\mathrm{FeCl}_{3}(0.1 \% \mathrm{w} / \mathrm{v})$. The absorbance was measured at $700 \mathrm{~nm}$ in UV-Vis spectrophotometer (UV-1800 Shimadzu). The experiment was performed in triplicates. The high value of the absorbance in reaction mixture indicated a greater reducing power of the fungal extract and AgNPs.

\section{Results and discussion}

Molecular identification of the fungal strain was done using ITS4 and ITS5 sequencing. The tested fungal strain showed 100\% sequence similarity with Talaromyces purpureogenus. Sequence analysis with NCBI accession number MK108916.1, Talaromyces purpureogenus strain KNUPD2 resulted in the following alignment statistics. Query length-531, score-958 bits (1062), Expect-0.0, Identities-531/531 (100\%), Gaps-0/531 (0\%), StrandPlus/Plus. The BLASTn and NCBI analyzed the sequence identification by homology search for the sequence closely related to the fungal species. This fungus holds the potency of secreting a variety of secondary metabolites. Secondary metabolites viz. Terpenoids and phenols have shown their presence in Talaromyces purpureogenus broth, however, tannins and alkaloids were found to be absent from both the broth extract and mycelial extract. These phenols possibly play a vital role in antioxidant properties of the materials. GC-MS analysis of

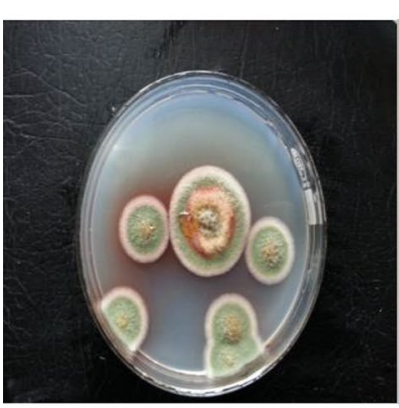

(a)

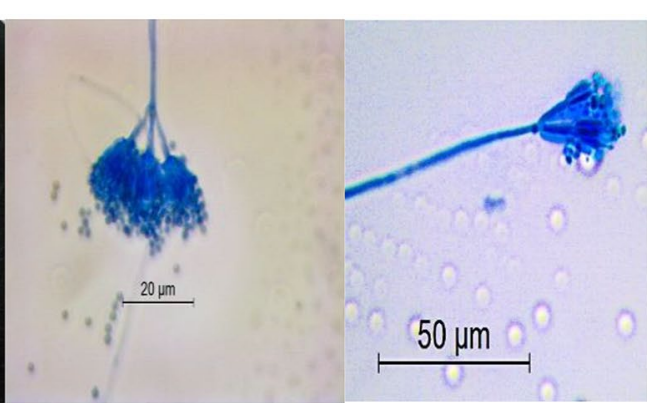

(b)

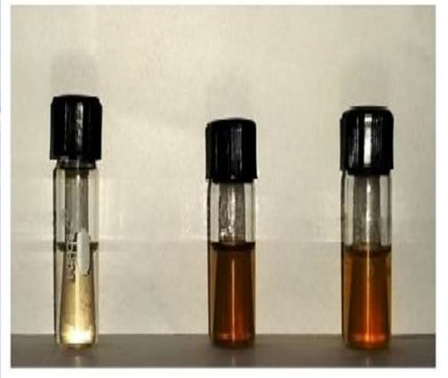

(d)

Fig. 1 a Talaromyces purpureogenus on solid agar medium. b, c T. purpureogenus microscopic image showing hyphae and spores. $\mathbf{d}$ Colour change of the reaction mixture after $24 \mathrm{~h}, 48 \mathrm{~h}$, and $72 \mathrm{~h}$ 


\section{$\underline{\text { UV-Vis spectroscopy of } 2 \mathrm{mM} \text { AgNP extract of } \quad \text { T.purpureogenus }}$}

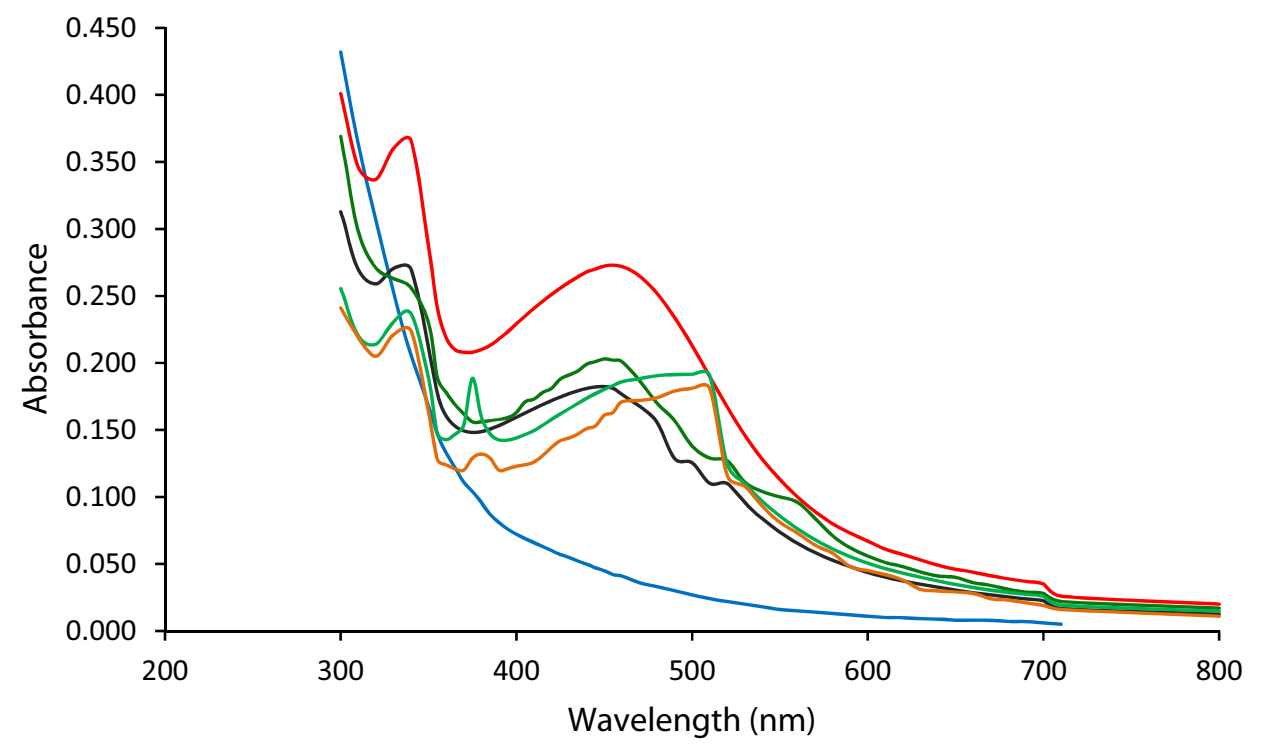

- After $12 \mathrm{~h}$

After $24 \mathrm{~h}$

- After $36 \mathrm{~h}$

- After $48 \mathrm{~h}$

- After $72 \mathrm{~h}$

- After $96 \mathrm{~h}$

Fig. 2 UV-Vis spectroscopy of $2 \mathrm{mM}$ AgNP extract of T. Purpureogenus

T. purpureogenus extract indicated the presence of 16 compounds when compared with NIST Database. Major compounds identified were Dibutyl phthalate, Phthalic acid, butyl hept-3-yl ester (57.90\%), 9, 12-Octadecadienoic acid, methyl ester (29.60\%), 2 amino-4-hydroxy 6methyl pyrimidine (4.17\%), and Apiol (2.31\%).

The colour of the reaction mixture i.e., mycelial extract and $\mathrm{AgNO}_{3}$ was observed at regular intervals which changed from white to orangish brown after $48 \mathrm{~h}$ (Fig. 1b, c). This color change can be correlated with the process of excitation of surface plasmon vibration within the biologically produced AgNPs [53]. In UV-vis spectroscopy a peak was obtained at $390-460 \mathrm{~nm}$ by UV-visible spectroscope (Fig. 2).

During the spectral analysis, spectroscopy was done at regular intervals predefined during standardization. Maximum absorbance was observed at $450 \mathrm{~nm}$ which is a characteristic surface plasmon resonance peak of mycosynthesized AgNPs [54], the results are similar to previous findings $[55,56]$. The peaks obtained at $438 \mathrm{~nm}$ wavelength probably give nanoparticles with size a size range of $60-80 \mathrm{~nm}$ [57]. These results are in accordance with the previous results [19, 58-61]. FTIR (Fig. 3) showed the bands at $3428.4 \mathrm{~cm}^{-1}$ confirming the presence of hydroxyl group, $\mathrm{H}-$ bonded $-\mathrm{OH}$ stretch [62]. A peak at $1621.9 \mathrm{~cm}^{-1}$ showed the presence of amides or primary amine with $\mathrm{N}-\mathrm{H}$ bend. A peak at $1383.9 \mathrm{~cm}^{-1}$ confirmed the presence of phenols or tertiary alcohol
-OH bend. A peak at $1076.1 \mathrm{~cm}^{-1}$ corresponds to $-\mathrm{C}-\mathrm{N}$ primary amine stretch or cyclic ether with large rings, $\mathrm{C}-\mathrm{O}$ stretch. Peaks at $1022.0 \mathrm{~cm}^{-1}$ correspond to aromatic $\mathrm{C}-\mathrm{H}$ in-plane bend. The peak at $516.0 \mathrm{~cm}^{-1}$ may corresponds to the presence of aryl disulfide $(\mathrm{S}-\mathrm{S})$ or Polysulfides (S-S stretch) or $\mathrm{C}-\mathrm{Br}$ stretch [63]. This concludes that these functional groups are somehow involved in the stabilization of AgNPs and act as a capping agent [64]. These results were in accordance with the previous results $[38,65]$.

DLS (dynamic light scattering) measurement with zeta potential was used to find out the average size of AgNPs (Fig. 4). The Z-average was $240.2 \mathrm{r} . n \mathrm{~m}$ with 0.720 , PdI value (Fig. 4a). Zeta potential having either high negative value or high positive value, show a tendency to repel each other thus declining the agglomeration $[65,66]$. The polydispersed nature of the nanoparticles is a result of highly negative zeta potential avoiding the formation of agglomerates leading to a concise stability. The obtained nanoparticles have zeta potential equal to $-19.5 \mathrm{mV}$ (Fig. 4b) attesting the repulsive nature of the silver nanoparticles leading to the stability $[67,68]$. Present X-ray diffraction analysis demonstrated that the nature of synthesized AgNPs is crystalline (Fig. 5). The XRD pattern of synthesized AgNPs is shown in Fig. 5. The result of XRD analysis indicated the $2 \theta$ value of $38^{\circ}, 46^{\circ}, 67^{\circ}$ and $78^{\circ}$ correspond to $111,200,220$, and 311 respectively to the planes of silver. The XRD results confirmed the 


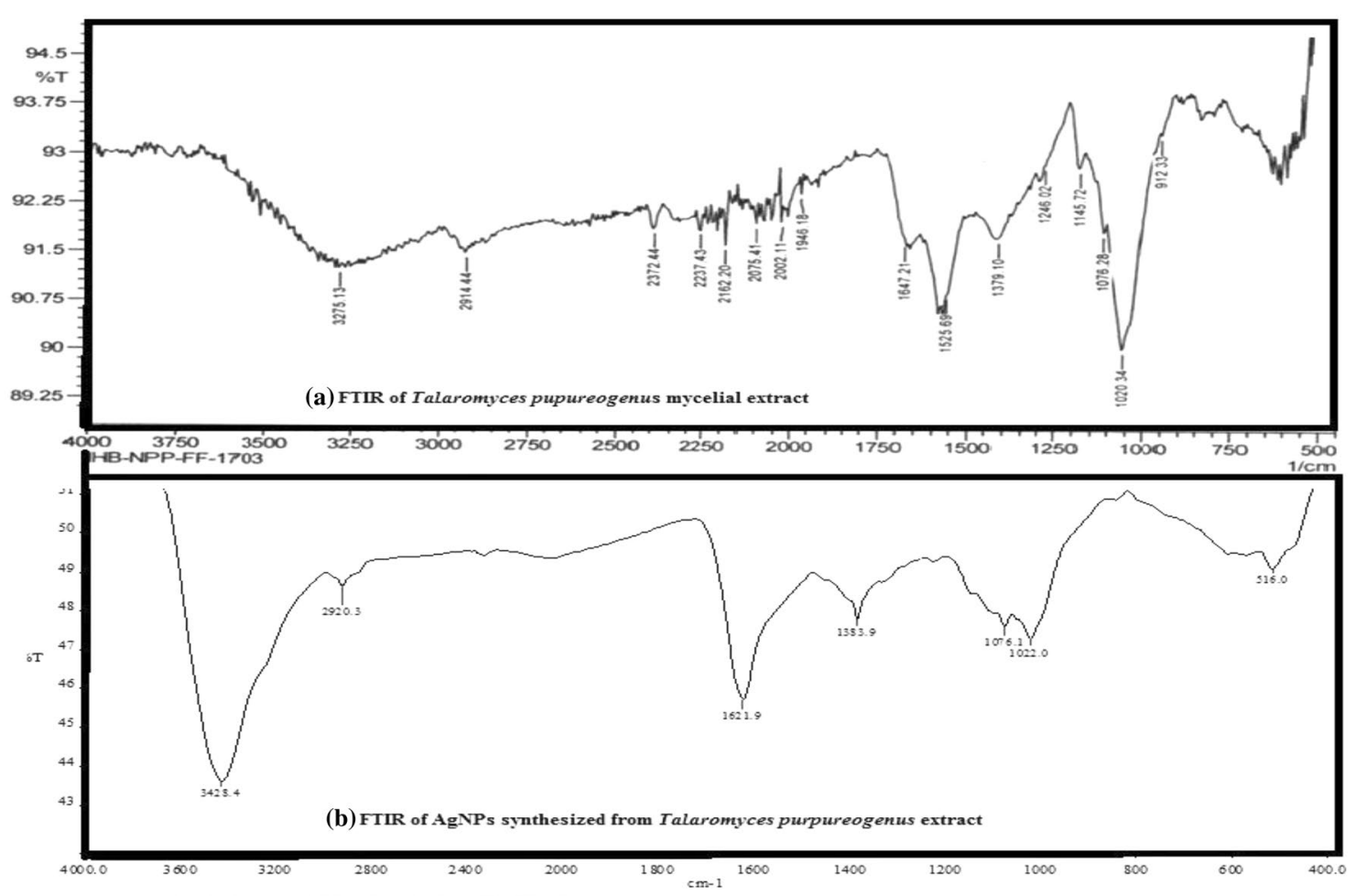

Fig. 3 FTIR showing peaks for specific functional groups, a fungal extract, b T. purpureogenus AgNPs

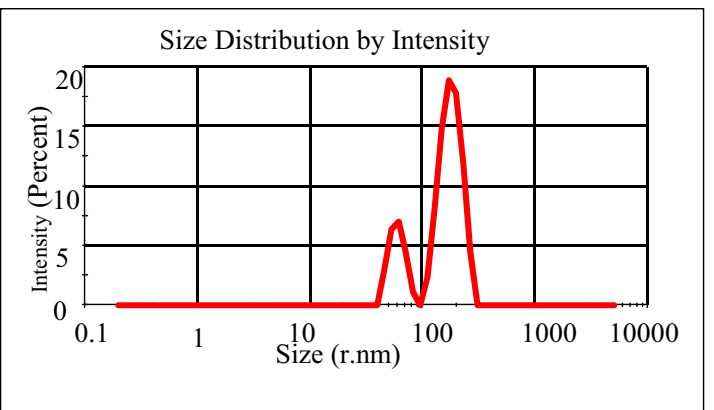

(a)

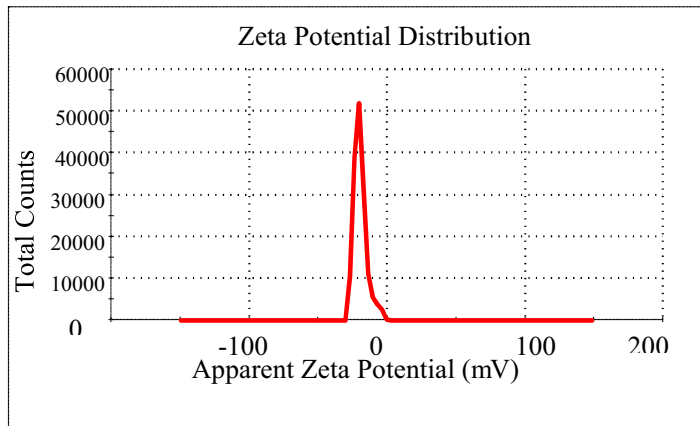

(b)

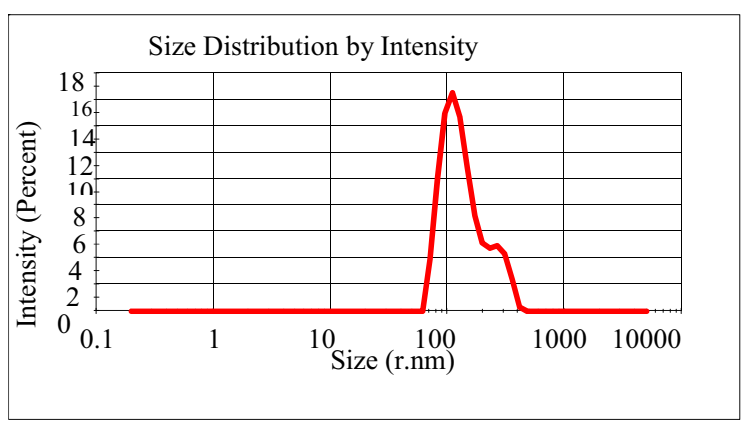

(c)

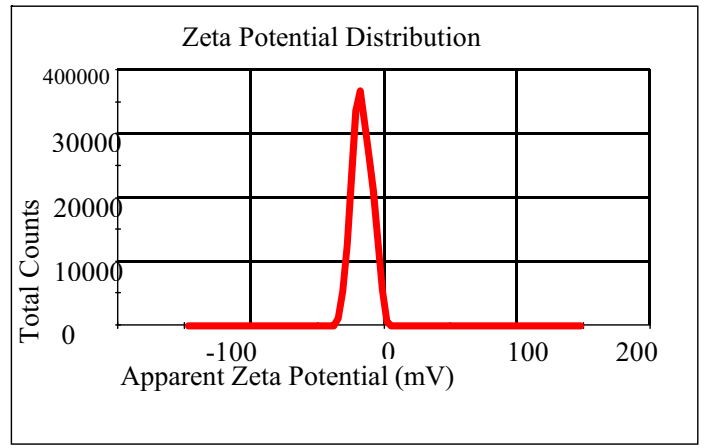

(d)

Fig. 4 DLS and Zeta Potential analysis of T. Purpureogenus AgNPs showing. a Size distribution by intensity first day. b Zeta Potential Distribution First day. c Size distribution by intensity after 60 days. $\mathbf{d}$ Zeta Potential Distribution after 60 days 


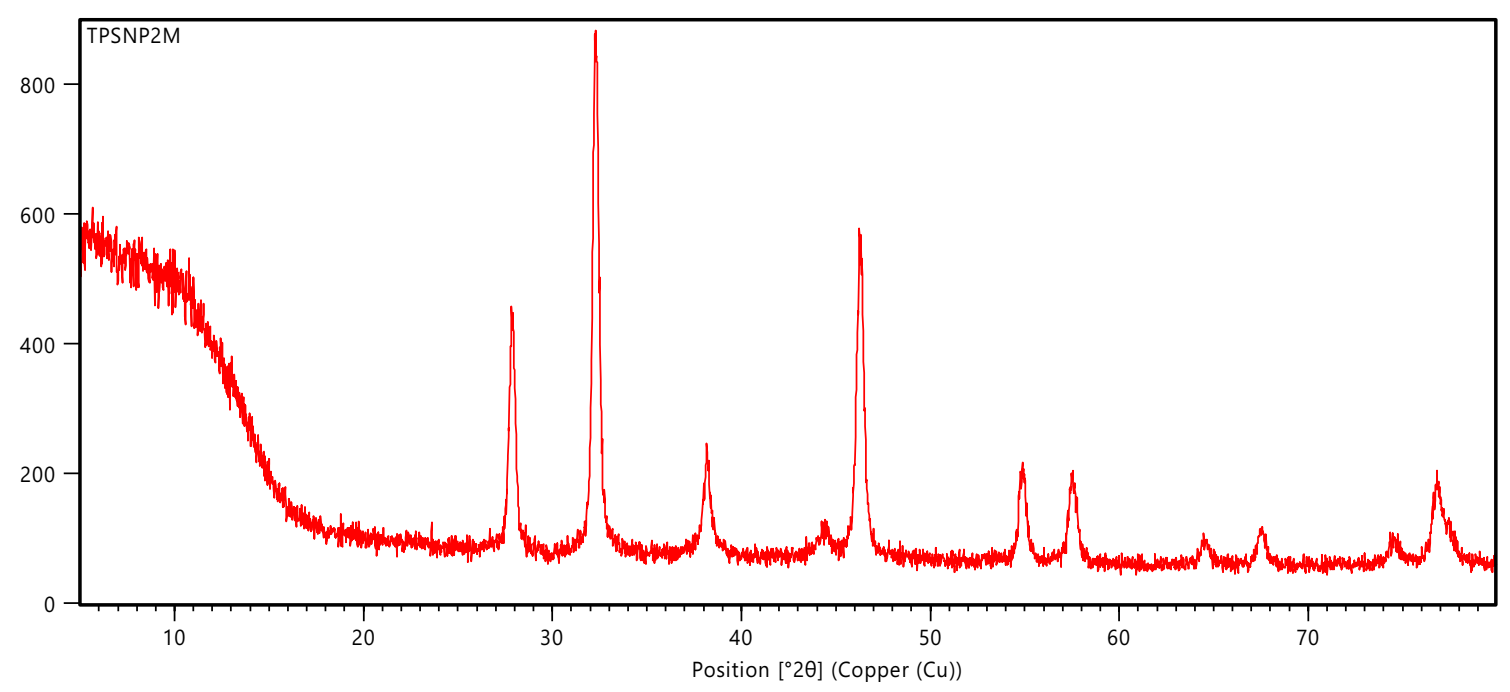

Fig. 5 XRD Analysis of AgNPs of T.purpureogenus

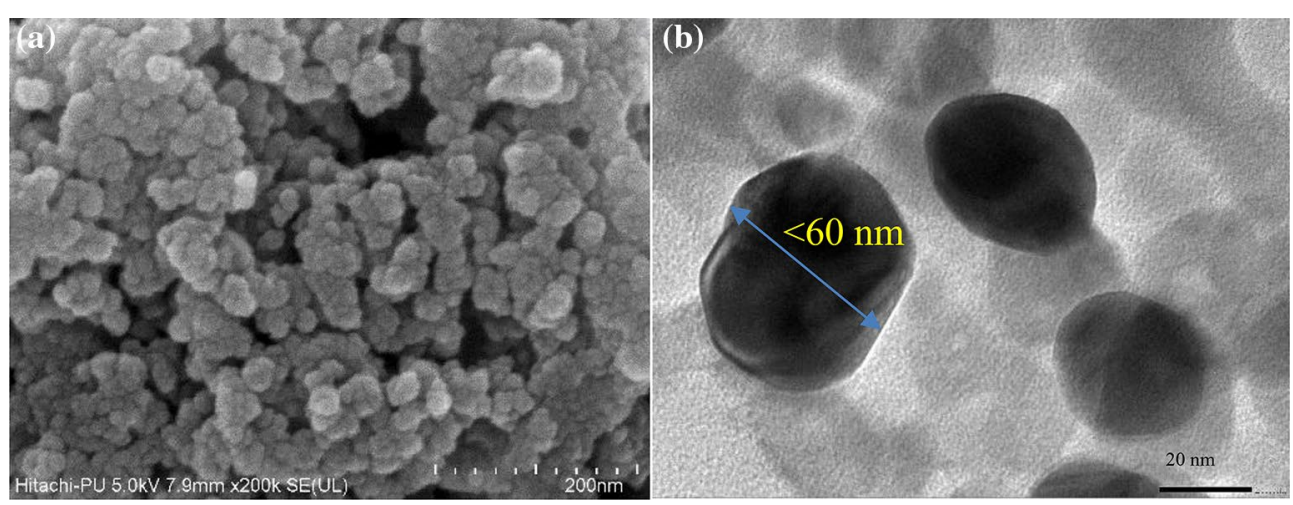

Fig. 6 a FEG-SEM image of the fungal AgNPs. b HRTEM image of fungal AgNPs

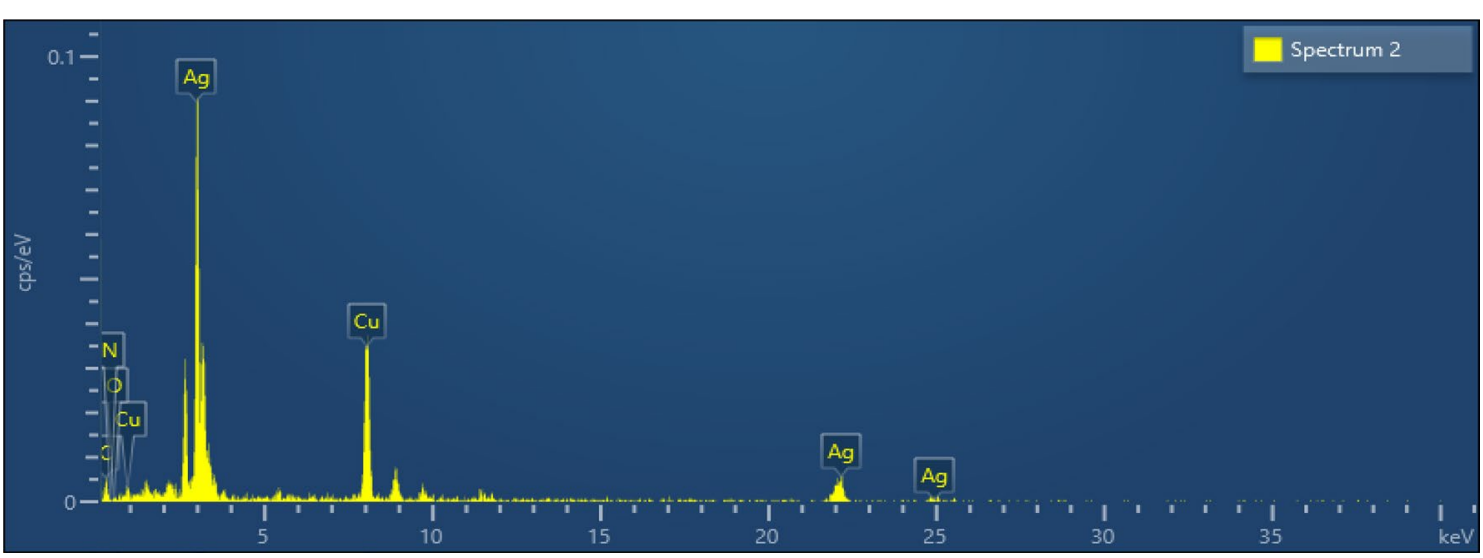

Fig. 7 EDS of AgNPs of T. purpureogenus 
occurrence of AgNPs. These results also confirmed the nature of AgNPs as crystalline face-centered cubic which is in agreement with the database of JCPDS (now called ICDD) file no. 04-0783. These results are as per the previous XRD results of biosynthesized AgNPs [17, 49, 56, 60, $69,70]$.

The morphological features of mycosynthesized AgNPs were observed in FEG-SEM (Fig. 6a) which showed a variety of shapes and sizes of AgNPs with few clump formations. AgNPs have shown cauliflower-like morphology in FEG-SEM (Fig. 6a), which are in accordance with the previous results [50]. HRTEM (Fig. 6b) results revealed that the synthesized AgNP's were round to oval/round shaped [71] and having a diameter ranging from 30 to $60 \mathrm{~nm}$. The EDX analysis confirmed the presence of $0.63 \%$ of Ag atoms. The HRTEM-EDS (Fig. 7) analysis showed the weight percent of Ag $67.26 \%$ and atomic percent $43.13 \%$. The presence of

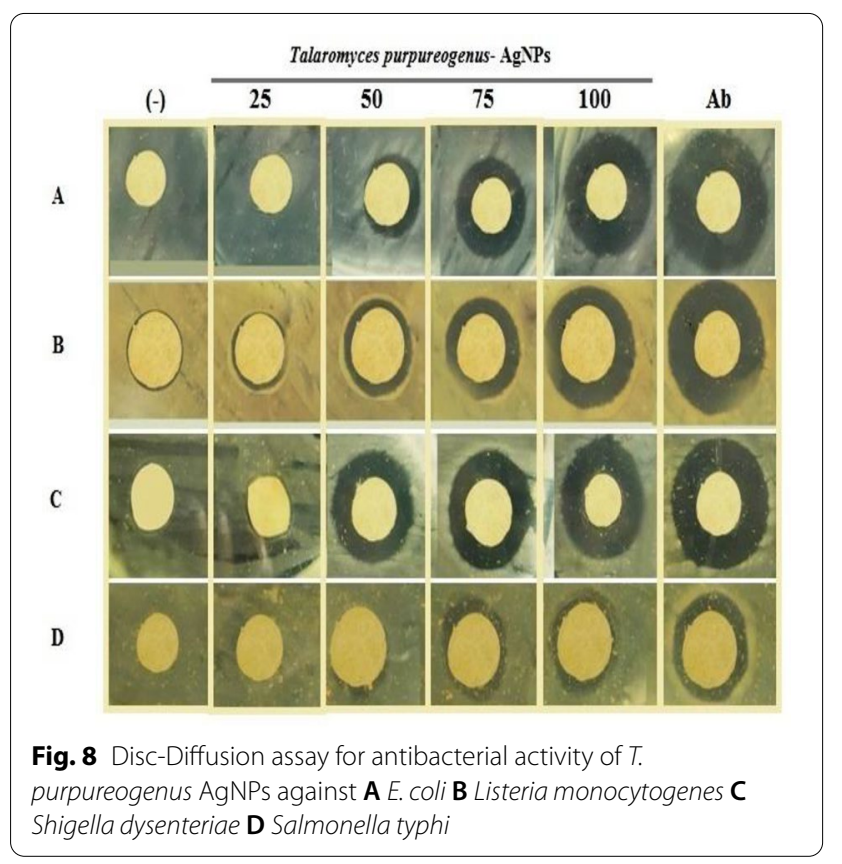

mycosynthesized AgNPs was confirmed by the specific peak at $3.0 \mathrm{keV}$ in EDS.

Peaks showing presence of carbon, oxygen and copper also appeared in EDS micrograph (Fig. 7). Generally, the samples are coated on copper-grid whose remnants may have resulted in the peak shown at $8 \mathrm{keV}$. These results were following the previous results $[55,58]$. The stability of the synthesized silver nanoparticles was observed for 50-60 days by three parameters viz. UV-vis spectroscopy, DLS analysis and FTIR analysis. Here, UVvis spectroscopy showed absorption peaks in range of 440-480 nm. Further, the Z-average size of AgNPs was 304.7 r.nm with PdI 0.807 (Fig. 4c). The zeta potential was observed to be $-16.6 \mathrm{mV}$, still a good quality result (Fig. 4d) The specific peaks at 3317.0, 1041.0 and $1589.0 \mathrm{~cm}^{-1}$ were observed quite similar to the points discussed earlier (Fig. 3). This stability of nanoparticles play a vital role in antimicrobial potential.

In the present study these mycosynthesized AgNPs showed a prominent antibacterial activity (Fig. 8) against a list of bacterias viz. E.coli, Shigella sp., Salmonella typhi (gram-negative), and Listeria sp. (gram-positive) which was similar to positive control vanomycin and ampicillin. The highest zone of inhibition was found to be in the case of $E$. coli $(17.00 \pm 0.14 \mathrm{~mm})$, followed by Shigella sp. $(18.00 \pm 0.21 \mathrm{~mm})$ and Salmonella typhi $(14.00 \pm 0.13 \mathrm{~mm})$. The lowest zone of inhibition was found to be in Listeria sp. $(13.00 \pm 0.29 \mathrm{~mm})$ (Table 1). These results were found to be in accordance with the previous reports [72-74]. Further, MIC analysis was opted for testing antibacterial activity against above 4 strains of bacteria. MIC of fungal extract for the different bacterial strains was $31.25 \mu \mathrm{g} / \mathrm{mL}$ (Listeria and Shigella), $125 \mu \mathrm{g} / \mathrm{mL}$ (E.coli) and $62.5 \mu \mathrm{g} / \mathrm{mL}$ (S. typhi). MIC of mycosynthesized silver nanoparticles for different bacterial strains was $1.5625 \mu \mathrm{g} / \mathrm{mL}$ (Listeria and Shigella), 0.78125 (E. coli) and 3.125 (S. typhi).

DPPH analysis (Fig. 9a) was performed for the assessment of antioxidant properties of the fungal extract and mycosynthesized AgNPs. The percent inhibition in the

Table 1 Antibacterial activity of T. purpureogenus AgNPs against (1) Listeria monocytogenes (2) Shigella dysenteriae (3) E. coli (4) Salmonella typhi

\begin{tabular}{|c|c|c|c|c|c|c|c|}
\hline Serial no. & Bacterial strain & $\begin{array}{l}\text { Positive control } \\
(+) \text { ampicillin/ } \\
\text { vanomycin }(\mathrm{mm})\end{array}$ & $\begin{array}{l}\text { Negative control } \\
\text { (-) DMSO (mm) }\end{array}$ & $\begin{array}{l}25 \mu \mathrm{g} / \mathrm{mL}(\mathrm{I}) \\
(\mathrm{mm})\end{array}$ & $\begin{array}{l}50 \mu \mathrm{g} / \mathrm{mL}(\mathrm{l}) \\
(\mathrm{mm})\end{array}$ & $\begin{array}{l}75 \mu \mathrm{g} / \mathrm{mL}(\mathrm{I}) \\
(\mathrm{mm})\end{array}$ & $\begin{array}{l}100 \mu \mathrm{g} / \mathrm{mL}(\mathrm{I}) \\
(\mathrm{mm})\end{array}$ \\
\hline 1 & $\begin{array}{l}\text { Listeria monocy- } \\
\text { togenes }\end{array}$ & $18 \pm 0.16$ & $6 \pm 0.17$ & $9 \pm 0.26$ & $11 \pm 0.42$ & $12 \pm 0.32$ & $14 \pm 0.29$ \\
\hline 2 & Shigella dysenteriae & $21 \pm 0.19$ & $6 \pm 0.16$ & $10 \pm 0.23$ & $15 \pm 0.16$ & $17 \pm 0.23$ & $18 \pm 0.21$ \\
\hline 3 & E. coli & $26 \pm 0.14$ & $6 \pm 0.16$ & $12 \pm 0.16$ & $16 \pm 0.19$ & $19 \pm 0.16$ & $23 \pm 0.14$ \\
\hline 4 & Salmonella typhi & $16 \pm 0.15$ & $6 \pm 0.17$ & $8 \pm 0.14$ & $12 \pm 0.15$ & $13 \pm 0.15$ & $15 \pm 0.13$ \\
\hline
\end{tabular}




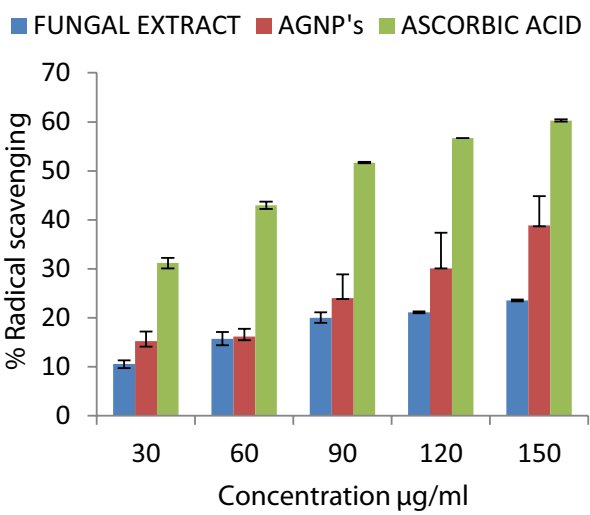

(a)

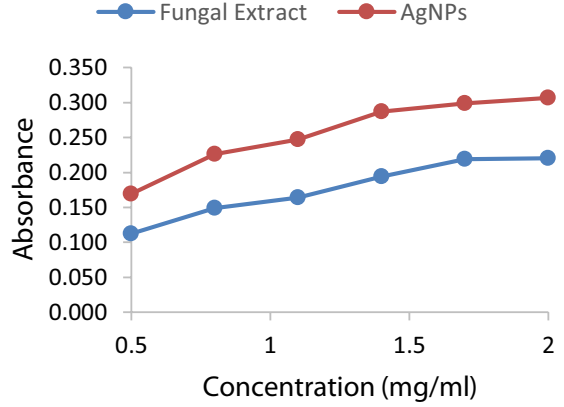

(b)

Fig. 9 Antioxidant assay. a DPPH Scavenging activity of T. purpureogenus mediated synthesized AgNPs. b Reducing power assay T. purpureogenus mediated synthesized AgNPs

case of the fungal extract was found to be $10.554 \%$ at lower concentration and $23.571 \%$ at high concentration; similarly, the percent inhibition in the case of mycosynthesized AgNPs was found to be $15.215 \%$ at lower concentration and $32.894 \%$ at high concentration. The $\mathrm{IC}_{50}$ values for fungal extract and AgNPs were 393.6361 and $250.3009 \mu \mathrm{g} / \mathrm{mL}$ respectively. The reducing potential was measured by change of $\mathrm{Fe}^{3+}$ to $\mathrm{Fe}^{2+}$. The AgNPs showed high absorbance value than the fungal extract (Fig. 9b) that indicated their enormous reductive potential and ability to donate electrons for free radical stabilization. From the results, it can be assumed that the mycosynthesized AgNPs performed better as antioxidant agents when compared to the fungal extract. This effective result can be beneficial to consider them a good source of natural antioxidant agents that can balance the antioxidant and ROS levels, resulting in the prevention of cell damage and degeneration of cellular contents.

\section{Conclusion}

Synthesis of metallic nanoparticles in a biological way had proven to be a method where the process is effective and less toxic. In the present study an endophytic fungus, Talaromyces purpureogenus was isolated from Taxus baccata Linn. The fungus showed its potency to reduce the $\mathrm{AgNO}_{3}$ to AgNPs where it produced high-quality crystalline AgNPs and its characterization was done using various techniques viz. UV-vis spectroscopy, FTIR, FEGSEM, HRTEM, and XRD. The functional groups found in FTIR analysis have a probable role as capping agents. The particles were found to have a size of about $49.3 \mathrm{~nm}$ with crystalline fcc nature. The AgNPs also showed their effect on both gram-positive and gram-negative bacteria. Thus, the results conclude that isolated fungus Talaromyces purpureogenus is a distinguished producer of differently shaped silver nanoparticles having effective antibacterial and antioxidant activities, which can further accomplish biomedical and industrial purposes channelizing a way to reduce the pressure Taxus baccata is facing due to unethical harvesting techniques employed because of its huge utilitarian value.

\section{Abbreviations}

${ }^{\circ} \mathrm{C}$ : Degree celcius; $\mu \mathrm{L}$ : Micro litre; $\mu \mathrm{m}$ : Micrometre; a.m.u: Atomic mass unit; Ag: Silver; AgNPs: AgNPs; cm: Centimetre; Da: Dalton; DLS: Dynamic light scattering; DMSO: Dimethyl sulfoxide; DPPH: 2,2'-Diphenyl-1-picrylhydrazyl; EDS: Energy dispersive X-ray diffraction; FCC: Face centered cubic; FEG-SEM: Field emission gun scanning electron microscopy; FTIR: Fourier transform infra red spectroscopy; g: Gram; GC-MS: Gas chromatography mass spectroscopy; h: Hour/hours; HCl: Hydrochloric acid; HRTEM: High resolution transmission electron microscopy; ICDD: International Centre of Diffraction Data; ITS: Internal transcribed spacers; JCPDS: Joint Committee on Power Diffraction Standards; L: Litre; Linn.: Linnaeus; MEEF: Mycelial extract of endophytic fungi; mg: Miligram; mg/L: Milligram/litre; MIC: Minimum inhibitory concentration; min: Minute; $\mathrm{mL}$ : Millilitre; mm: Millimetre; $\mathrm{mM}$ : Millimolar; $\mathrm{mV}$ : Millivolt; $\mathrm{nm}$ : Nanometre; PCR: Polymerase chain reaction; PDA: Potato dextrose agar; PDB: Potato dextrose broth; Pdl: Polydispersity index; r.nm: Radius in nanometre; rpm: Rotation per minute; sec: Second; UV-Vis: Ultra-violet visible spectroscopy; XRD: X-ray diffraction.

\section{Acknowledgements}

We would like to thank the Department of Biosciences, H.P.U. Shimla for the laboratory assistance. We would particularly thank CSIR-CSIO Chandigarh, PU-SAIF, and PU-CIL facility for different types of characterization. We would particularly like to thank Dr. S.K Singh, Scientist, National Facility (NFCCl and FIS) ARI, Pune; for molecular identification of fungal species. No funds or grants or other support was received.

\section{Authors' contibutions}

All the authors read and approved the final manuscript.

Funding

No Funding/Grant was received for this research work. 


\section{Declarations}

\section{Competing interests}

The authors declare that they have no competing interests.

\section{Author details}

${ }^{1}$ Department of Biosciences, Himachal Pradesh University, Summerhill, Shimla 171005, Himachal Pradesh, India. ${ }^{2}$ Department of Genetics, Maharishi Dayanand University, Rohtak 124001, Haryana, India.

Received: 12 November 2021 Accepted: 8 January 2022 Published online: 20 January 2022

\section{References}

1. Chaturvedi S, Dass S (2011) Traditional medicinal and economic uses of gymnosperms. Bull Environ Pharmacol Life Sci 1(1):70-72

2. Cameron SI, Smith RF (2002) Bringing "blue sky biology" down to earth: linking natural products research with commercialization. Proceedings of the 29th Annual Meeting of the Plant Growth Regulation Society of America, Halifax

3. Beckstrom-Sternberg SM, Duke JA (1993) International Yew Resource Conference, Berkeley, p 3

4. Mukherjee A, Joshi K, Pal RS, Atheequlla GA, Roy ML, Chandra N (2018) Scientific health benefits of namakeen chai/jya (salted tea): a traditional tea beverage of Bhotiya tribal community in higher altitudes of Uttarakhand. Indian J Tradit Knowl 17:365-369

5. Gaur RD (1999) Flora of the district Garhwal, North West Himalaya. Transmedia, Srinagar

6. Talebi M, Ghassempour A, Talebpour Z, Rassouli A, Dolatyari L (2004) Optimization of the extraction of paclitaxel from Taxus baccata L. by the use of microwave energy. J Sep Sci 27(13):1130-1136

7. Malik S, Cusidó RM, Mirjalili MH, Moyano E, Palazón J, Bonfill M (2011) Production of the anticancer drug taxol in Taxus baccata suspension cultures: a review. Process Biochem 46(1):23-34

8. Purohit A, Maikhuri RK, Rao KS, Nautiyal S (2001) Impact of bark removal on survival of Taxus baccata L. (Himalayan yew) in Nanda Devi biosphere reserve, Garhwal Himalaya, India. Curr Sci 81:586-590

9. Nimasow G, Dai Nimasow O, Tsering G (2015) Vanishing Taxus baccata L. due to unsustainable exploitation and climate change in west Kameng and Tawang districts of Arunachal Pradesh. Earth 4(3-1):11-18

10. Piovesan G, Saba EP, Biondi F, Alessandrini A, Di Filippo A, Schirone B (2009) Population ecology of yew (Taxus baccata L.) in the Central Apennines: spatial patterns and their relevance for conservation strategies. Plant Ecol 205(1):23-46

11. Adhikari P, Pandey A (2020) Bioprospecting plant growth promoting endophytic bacteria isolated from Himalayan yew (Taxus wallichiana Zucc.). Microbiol Res 239:126536

12. Ankush S, Anand S, Madhavi J (2017) Diversity of fungi associated with Taxus baccata Linn. in different seasons. Indian For 143(4):380-384

13. Ashkezari SJ, Fotouhifar KB (2017) Diversity of endophytic fungi of common yew (Taxus baccata L.) in Iran. Mycol Prog 16(3):247-256

14. Chaurasia B, Pandey A, Palni LMS (2005) Occurrence of arbuscular mycorrhizae in the rhizosphere of Himalayan Yew [Taxus baccata L. subsp. wallichiana (Zucc.) Pilger] — a case study. Basic research and applications of Mycorrhizae. IK International Pvt. Ltd., New Delhi, pp 26-35

15. Yuan Jl, Jian-Nan Bl, Bing YAN, Xu-Dong Z (2006) Taxol-producing fungi: a new approach to industrial production of taxol. Chin J Biotechnol 22(1):1-6

16. Wani ZA, Ashraf N, Mohiuddin T, Riyaz-UI-Hassan S (2015) Plant-endophyte symbiosis, an ecological perspective. Appl Microbiol Biotechnol 99(7):2955-2965

17. Li G, He D, Qian Y, Guan B, Gao S, Cui Y, Yokoyama K, Wang L (2012) Fungus-mediated green synthesis of silver nanoparticles using Aspergillus terreus. Int J Mol Sci 13(1):466-476

18. Kajani AA, Bordbar AK, Esfahani SHZ, Khosropour AR, Razmjou A (2014) Green synthesis of anisotropic silver nanoparticles with potent anticancer activity using Taxus baccata extract. RSC Adv 4(106):61394-61403
19. Kajani AA, Zarkesh-Esfahani SH, Bordbar AK, Khosropour AR, Razmjou A Kardi M (2016) Anticancer effects of silver nanoparticles encapsulated by Taxus baccata extracts. J Mol Liq 223:549-556

20. Sreekanth D, Syed A, Sarkar S, Sarkar D, Santhakumari B, Ahmad A, Khan MI (2009) Production, purification, and characterization of taxol and 10-DABIII from a new endophytic fungus Gliocladium sp. isolated from the Indian Yew Tree, Taxus baccata. J Microbiol Biotechnol 19(11):1342-1347

21. Bhatnagar S, Kobori T, Ganesh D, Ogawa K, Aoyagi H (2019) Biosynthesis of silver nanoparticles mediated by extracellular pigment from Talaromyces purpurogenus and their biomedical applications. Nanomaterials 9(7):1042

22. Hu X, Kandasamy Saravanakumar TJ, Wang MH (2019) Mycosynthesis, characterization, anticancer and antibacterial activity of silver nanoparticles from endophytic fungus Talaromyces purpureogenus. Int J Nanomed 14:3427

23. Wang L, Wu Y, Xie J, Wu S, Wu Z (2018) Characterization, antioxidant and antimicrobial activities of green synthesized silver nanoparticles from Psidium guajava L. leaf aqueous extracts. Mater Sci Eng C 86:1-8

24. Khan I, Saeed K, Khan I (2019) Nanoparticles: properties, applications and toxicities. Arab J Chem 12(7):908-931

25. Shreyash N, Sonker M, Bajpai S, Tiwary SK (2021) Review of the mechanism of nanocarriers and technological developments in the field of nanoparticles for applications in cancer theragnostics. ACS Appl Bio Mater 4(3):2307-2334

26. Mojab F, Kamalinejad M, Ghaderi N, Vahidipour HR (2010) Phytochemical screening of some species of Iranian plants. Iran J Pharmaceut Res 2:77-82

27. Saravanakumar K, Sriram B, Sathiyaseelan A, Mariadoss AVA, Hu X, Han KS et al (2021) Synthesis, characterization, and cytotoxicity of starchencapsulated biogenic silver nanoparticle and its improved anti-bacterial activity. Int J Biol Macromol 182:1409-1418

28. Mukherjee P, Ahmad A, Mandal D, Senapati S, Sainkar SR, Khan Ml et al (2001) Fungus-mediated synthesis of silver nanoparticles and their immobilization in the mycelial matrix: a novel biological approach to nanoparticle synthesis. Nano Lett 1(10):515-519

29. Li WR, Xie XB, Shi QS, Zeng HY, You-Sheng OY, Chen YB (2010) Antibacterial activity and mechanism of silver nanoparticles on Escherichia coli. Appl Microbiol Biotechnol 85(4):1115-1122

30. Chernousova S, Epple M (2013) Silver as antibacterial agent: ion, nanoparticle, and metal. Angew Chem Int Ed 52(6):1636-1653

31. Gurunathan S, Park JH, Han JW, Kim JH (2015) Comparative assessment of the apoptotic potential of silver nanoparticles synthesized by Bacillus tequilensis and Calocybe indica in MDA-MB-231 human breast cancer cells: targeting p53 for anticancer therapy. Int J Nanomed 10:4203

32. Bharde A, Rautaray D, Bansal V, Ahmad A, Sarkar I, Yusuf SM, Sanyal M, Sastry M (2006) Extracellular biosynthesis of magnetite using fungi. Small 2(1):135-141

33. Bhainsa KC, D'souza SF (2006) Extracellular biosynthesis of silver nanoparticles using the fungus Aspergillus fumigatus. Colloids Surf B 47(2):160-164

34. Mukherjee P, Roy M, Mandal BP, Dey GK, Mukherjee PK, Ghatak J, Tyagi AK, Kale SP (2008) Green synthesis of highly stabilized nanocrystalline silver particles by a non-pathogenic and agriculturally important fungus $T$. asperellum. Nanotechnology 19(7):075103

35. Afify TA, Saleh HH, Ali Zl (2017) Structural and morphological study of gamma-irradiation synthesized silver nanoparticles. Polym Compos 38(12):2687-2694

36. Shaheen MN, El-hadedy DE, Ali ZI (2019) Medical and microbial applications of controlled shape of silver nanoparticles prepared by ionizing radiation. BioNanoScience 9(2):414-422

37. Govindappa M, Farheen H, Chandrappa CP, Rai RV, Raghavendra VB (2016) Mycosynthesis of silver nanoparticles using extract of endophytic fungi, Penicillium species of Glycosmis mauritiana, and its antioxidant, antimicrobial, anti-inflammatory and tyrokinase inhibitory activity. Adv Nat Sci 7(3):035014

38. Farsi M, Farokhi S (2018) Biosynthesis of antibacterial silver nanoparticles by endophytic fungus Nemania sp. isolated from Taxus baccata L. (Iranian yew). Zahedan J Res Med Sci. https://doi.org/10.5812/zjrms.57916 
39. Schulz B, Wanke U, Draeger S, Aust HJ (1993) Endophytes from herbaceous plants and shrubs: effectiveness of surface sterilization methods. Mycol Res 97(12):1447-1450

40. Suryanarayanan TS, Thennarasan S (2004) Temporal variation in endophyte assemblages of Plumeria rubra leaves. Fungal Divers 15:197-204

41. Saravanakumar K, Wang MH (2018) Trichoderma based synthesis of antipathogenic silver nanoparticles and their characterization, antioxidant and cytotoxicity properties. Microb Pathog 114:269-273

42. Saravanakumar K, Shanmugam S, Varukattu NB, MubarakAli D, Kathiresan K, Wang MH (2019) Biosynthesis and characterization of copper oxide nanoparticles from indigenous fungi and its effect of photothermolysis on human lung carcinoma. J Photochem Photobiol B 190:103-109

43. Radji M, Sumiati A, Rachmayani R, Elya B (2011) Isolation of fungal endophytes from Garcinia mangostana and their antibacterial activity. Afr J Biotech 10(1):103-107

44. Yadav M, Yadav A, Yadav JP (2014) In vitro antioxidant activity and total phenolic content of endophytic fungi isolated from Eugenia jambolana Lam. Asian Pac J Trop Med 7:S256-S261

45. Bhimba BV, Meenupriya J, Joel EL, Naveena DE, Kumar S, Thangaraj M (2010) Antibacterial activity and characterization of secondary metabolites isolated from mangrove plant Avicennia officinalis. Asian Pac J Trop Med 3(7):544-546

46. Devi NN, Shankar DP, Sutha S (2012) Biomimetic synthesis of silver nanoparticles from an endophytic fungus and their antimicrobial efficacy. Int J Biomed Adv Res 3:409-415

47. Rani R, Sharma D, Chaturvedi M, Yadav JP (2017) Green synthesis, characterization and antibacterial activity of silver nanoparticles of endophytic fungi Aspergillus terreus. J Nanomed Nanotechnol. https://doi.org/10. 4172/2157-7439.1000457

48. Sandhu SS, Shukla H, Shukla S (2017) Biosynthesis of silver nanoparticles by endophytic fungi: its mechanism, characterization techniques and antimicrobial potential. Afr J Biotech 16(14):683-698

49. Brumfitt W, Hamilton-Miller JM, Franklin I (1990) Antibiotic activity of natural products: 1. Propolis. Microbios 62(250):19-22

50. Sarkar S, Jana AD, Samanta SK, Mostafa G (2007) Facile synthesis of silver nano particles with highly efficient anti-microbial property. Polyhedron 26(15):4419-4426

51. Blois MS (1958) Antioxidant determinations by the use of a stable free radical. Nature 181(4617):1199-1200

52. Oyaizu M (1986) Studies on products of browning reaction antioxidative activities of products of browning reaction prepared from glucosamine. Jpn J Nutr Diet 44(6):307-315

53. Awwad AM, Salem NM, Abdeen AO (2013) Green synthesis of silver nanoparticles using carob leaf extract and its antibacterial activity. Int J Ind Chem 4(1):1-6

54. Krishnaraj C, Jagan EG, Rajasekar S, Selvakumar P, Kalaichelvan PT, Mohan NJCSBB (2010) Synthesis of silver nanoparticles using Acalypha indica leaf extracts and its antibacterial activity against water borne pathogens. Colloids Surf B 76(1):50-56

55. Tyagi S, Tyagi PK, Gola D, Chauhan N, Bharti RK (2019) Extracellular synthesis of silver nanoparticles using entomopathogenic fungus: characterization and antibacterial potential. SN Appl Sci 1(12):1-9

56. Nair AS, Pradeep T (2003) Halocarbon mineralization and catalytic destruction by metal nanoparticles. Curr Sci 84:1560-1564

57. Sathiyaseelan A, Saravanakumar K, Mariadoss AVA, Wang MH (2020) Biocompatible fungal chitosan encapsulated phytogenic silver nanoparticles enhanced antidiabetic, antioxidant and antibacterial activity. Int J Biol Macromol 153:63-71

58. Devi LS, Joshi SR (2015) Ultrastructures of silver nanoparticles biosynthesized using endophytic fungi. J Microsc Ultrastruct 3(1):29-37

59. Jyoti K, Baunthiyal M, Singh A (2016) Characterization of silver nanoparticles synthesized using Urtica dioica Linn. leaves and their synergistic effects with antibiotics. J Radiat Res Appl Sci 9(3):217-227

60. Madakka M, Jayaraju N, Rajesh N (2018) Mycosynthesis of silver nanoparticles and their characterization. MethodsX 5:20-29

61. Yazdi MET, Khara J, Housaindokht MR, Sadeghnia HR, Bahabadi SE, Amiri MS, Mosawee H, Taherzadeh D, Darroudi M (2019) Role of Ribes khorassanicum in the biosynthesis of AgNPs and their antibacterial properties. IET Nanobiotechnol 13(2):189-192

62. Prakash P, Gnanaprakasam P, Emmanuel R, Arokiyaraj S, Saravanan M (2013) Green synthesis of silver nanoparticles from leaf extract of
Mimusops elengi Linn. for enhanced antibacterial activity against multi drug resistant clinical isolates. Colloids Surf B 108:255-259

63. Manikprabhu D, Lingappa K (2013) Microwave assisted rapid and green synthesis of silver nanoparticles using a pigment produced by Streptomyces coelicolor klmp33. Bioinorg Chem Appl. https://doi.org/10.1155/2013/ 341798

64. Aravinthan A, Govarthanan M, Selvam K, Praburaman L, Selvankumar T, Balamurugan R, Kamala-Kannan S, Kim JH (2015) Sunroot mediated synthesis and characterization of silver nanoparticles and evaluation of its antibacterial and rat splenocyte cytotoxic effects. Int J Nanomed 10:1977

65. Singh T, Jyoti K, Patnaik A, Singh A, Chauhan R, Chandel SS (2017) Biosynthesis, characterization and antibacterial activity of silver nanoparticles using an endophytic fungal supernatant of Raphanus sativus. J Genet Eng Biotechnol 15(1):31-39

66. Roy S, Mukherjee T, Chakraborty S, das Kumar T (2013) Biosynthesis, characterisation and antifungal activity of silver nanoparticles by the fungus Aspergillus foetidus MTCC8876. Digest J NanomaterBiostruct 8:197-205

67. Shaligram NS, Bule M, Bhambure R, Singhal RS, Singh SK, Szakacs G, Pandey A (2009) Biosynthesis of silver nanoparticles using aqueous extract from the compactin producing fungal strain. Process Biochem 44(8):939-943

68. Suresh AK, Doktycz MJ, Wang W, Moon JW, Gu B, Meyer HM III et al (2011) Monodispersed biocompatible silver sulfide nanoparticles: facile extracellular biosynthesis using the $\gamma$-proteobacterium Shewanella oneidensis. Acta Biomat 7(12):4253-4258

69. Kotakadi VS, Gaddam SA, Venkata SK, Sarma PVGK, Sai Gopal DVR (2016) Biofabrication and spectral characterization of silver nanoparticles and their cytotoxic studies on human CD34 + ve stem cells. Biotech 6(2):216

70. Balaji DS, Basavaraja S, Deshpande R, Mahesh DB, Prabhakar BK, Venkataraman A (2009) Extracellular biosynthesis of functionalized silver nanoparticles by strains of Cladosporium cladosporioides fungus. Colloids Surf B 68(1):88-92

71. Chen JC, Lin ZH, Ma XX (2003) Evidence of the production of silver nanoparticles via pretreatment of Phoma sp. 3.2883 with silver nitrate. Lett Appl Microbiol 37(2):105-108

72. Okafor F, Janen A, Kukhtareva T, Edwards V, Curley M (2013) Green synthesis of silver nanoparticles, their characterization, application and antibacterial activity. Int J Environ Res Public Health 10(10):5221-5238

73. Lee W, Kim KJ, Lee DG (2014) A novel mechanism for the antibacterial effect of silver nanoparticles on Escherichia coli. Biometals 27(6):1191-1201

74. Nurul Aini A, Al Farraj DA, Endarko E, Rubiyanto A, Nur H, Al Khulaifi MM Hadibarata T, Syafiuddin A (2019) A new green method for the synthesis of silver nanoparticles and their antibacterial activities against grampositive and gram-negative bacteria. J Chin Chem Soc 66(7):705-712

\section{Publisher's Note}

Springer Nature remains neutral with regard to jurisdictional claims in published maps and institutional affiliations.

\section{Submit your manuscript to a SpringerOpen ${ }^{\circ}$ journal and benefit from:}

- Convenient online submission

- Rigorous peer review

- Open access: articles freely available online

- High visibility within the field

- Retaining the copyright to your article

Submit your next manuscript at springeropen.com 